\title{
Obesity and shift work: chronobiological aspects
}

\author{
L. C. Antunes ${ }^{1}$, R. Levandovski ${ }^{1}$, G. Dantas ${ }^{1}$, W. Caumo ${ }^{1,2,3}$ and M. P. Hidalgo ${ }^{1,4 *}$ \\ ${ }^{1}$ Post-Graduation Program in Medical Sciences, School of Medicine, Universidade Federal do Rio \\ Grande do Sul (UFRGS), Porto Alegre, Brazil \\ ${ }^{2}$ Pharmacology Department, Instituto de Ciências Básicas da Saúde of UFRGS, Porto Alegre, Brazil \\ ${ }^{3}$ Anesthesia and Perioperative Medicine Service at Hospital de Clínicas de Porto Alegre (HCPA), \\ UFRGS, Porto Alegre, Brazil \\ ${ }^{4}$ Human Chronobiology Program of HCPA, Psychiatric and Legal Medicine Department, Medical School, \\ UFRGS, Porto Alegre, Brazil
}

\begin{abstract}
The present review has the objective of summarising chronobiological aspects of shift work and obesity. There was a systematic search in PubMed databases, using the following descriptors: shift work; obesity; biological clock. Shift work is extremely frequent in several services and industries, in order to systematise the needs for flexibility of the workforce, necessary to optimise productivity and business competitiveness. In developing countries, this population represents a considerable contingent workforce. Recently, studies showed that overweight and obesity are more prevalent in shift workers than day workers. In addition, the literature shows that shift workers seem to gain weight more often than those workers submitted to a usual work day. In conclusion, there is considerable epidemiological evidence that shift work is associated with increased risk for obesity, diabetes and CVD, perhaps as a result of physiological maladaptation to chronically sleeping and eating at abnormal circadian times. The impact of shift work on metabolism supports a possible pathway to the development of obesity and its co-morbities. The present review demonstrated the adverse cardiometabolic implications of circadian misalignment, as occurs chronically with shift workers.
\end{abstract}

Shift work: Obesity: Biological clock

Shift work is extremely frequent in several services and industries, in order to systematise the needs for flexibility of the workforce, necessary to optimise productivity and business competitiveness. Shift work is defined as work primarily outside of normal daytime working hours ${ }^{(1)}$. In developing countries, this population represents a considerable contingent workforce. Recently, studies showed that overweight and obesity are more prevalent in shift workers than day workers ${ }^{(2,3)}$. In addition, the literature shows that shift workers seem to gain weight more often than those workers submitted to a usual work day ${ }^{(2-4)}$.

Modern society has come to rely increasingly on $24 \mathrm{~h}$ operations in many diverse settings and as many as $20 \%$ of workers in industrialised nations are shift workers ${ }^{(2,5)}$. The circadian rhythm and environmental conditions can become desynchronised in rotating shift workers whose night activity is out of phase with many coupled rhythms due to desynchronisation of the normal phase relationships between biological rhythms within the circadian system.
It is well known that the timing of sleep is under the control of the circadian pacemaker. Humans are a diurnal species; they sleep mostly at night, and they do so at approximately $24 \mathrm{~h}$ intervals. If they do not adhere to this general pattern, for instance when working night shifts, they experience the influence of their circadian clock $^{(6)}$. Also, shift workers may develop sleep disturbances when the relationship between light-dark phase, sleepiness and food intake is desynchronised.

Shift work is associated with various health problems caused by the disturbance of these biological rhythms. In spite of this, overweight and obesity may elicit a series of diseases, resulting in a public health problem. The WHO predicted that about 1.6 billion adults are overweight, and at least 400 million individuals are obese. Therefore, the WHO estimates that there will be 2.3 billion overweight adults in 2015, and that the number of obese individuals will reach 700 million. As BMI increases, it also becomes a greater risk factor for chronic diseases. A high BMI is a risk factor

Abbreviation: SCN, suprachiasmatic nucleus.

* Corresponding author: Dr Maria Paz Hidalgo, fax +55 513333 97333, email mpaz@cpovo.net 
for a series of pathological conditions such as: coronary diseases which are responsible for 17 million deaths per year; diabetes which has become a global epidemic and will increase by $50 \%$ in the next 10 years $^{(7)}$.

The present review summarises data found in the literature about circadian disruption and its relationship to obesity and metabolic disturbances frequently presented by shift workers.

\section{Materials and methods}

To introduce the central theme of the present review, we searched for experimental, observational and double-blind controlled randomised clinical trials. We used the MEDLINE (1960-2008) and Cochrane sites in our search strategy to locate the studies. Our language choices were English, Portuguese, Spanish, French and Italian. For this article compilation, we used the following keywords: 'shift work and obesity'; 'shift work and overweight'; 'shift work and BMI'; 'shift work and metabolic syndrome'. We found 212 articles based on the above search approach and selected ninety-five (Fig. 1). We excluded the articles that were caught in the search strategy at several levels and this was a reason for the reduction of numbers of articles. The inclusion criterion adopted was the obligatory presence in the abstract of the relationship between shift work and metabolic conditions, such as dyslipidaemia, the metabolic syndrome, CVD, alterations of lipidic and glycidic metabolisms, which could be triggered or promoted by shift work.
The impact of shift work on anthropometric parameters

Recent studies have shown that overweight and obesity are more prevalent in shift workers than day workers. In addition, the literature shows that shift workers seem to gain weight more often than those workers with the usual work day ${ }^{(2-4,8)}$. Shift workers in the selected studies showed variability in overweight and obesity prevalence of about 47.2 and $2.8 \%$, respectively. Nevertheless, in another study this difference was attributed not only to shift work, but also to the fact that the mean age of day workers was significantly higher ${ }^{(4)}$.

A study showed overweight and obesity prevalences of 62.4 and $15.7 \%$, respectively. The authors demonstrated that shift work is associated with BMI independent of age or time in shift work. These data become even more relevant when we consider that this research was conducted in the Mediterranean region ${ }^{(2)}$. The findings are in accordance with the literature, in which shift workers presented higher BMI, although studies concerning the time of exposure to this kind of labour pattern are controversial. In comparing 787 day workers and 787 day-night shift workers, duration of shift work exposure was a highly significant predictor among the day-night shift workers, after controlling for age. The authors concluded that a longer exposure predicts a higher $\mathrm{BMI}^{(4)}$. Also job stress and long working hours seem to contribute to an increase in $\mathrm{BMI}^{(3)}$.

A study conducted in Norway covering the period from 1979 to 2001 correlated BMI to shift work $^{(9)}$. The association between psychosocial work conditions and BMI seemed to be related to both the effort at work and the time of work, for males. Although the choice of participants

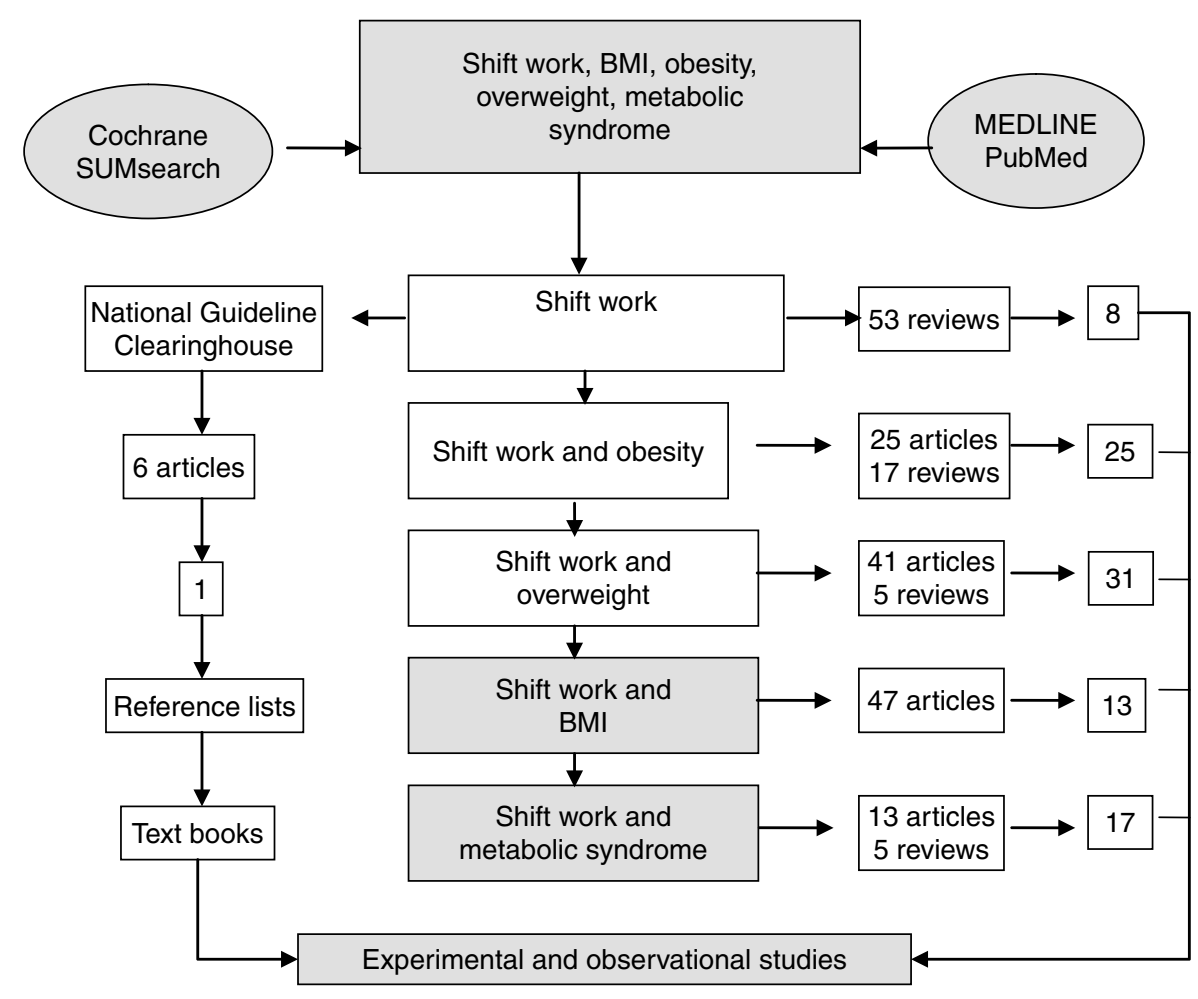

Fig. 1. Steps in the review. 
was conducted in a random way, this study was limited because weight and height were self-reported and not measured $^{(3)}$. There are studies where obesity was more prevalent in female shift workers than males for all ages studied $^{(10)}$. The association between shift work, age and BMI showed that obese subjects $\left(\mathrm{BMI}>30 \mathrm{~kg} / \mathrm{m}^{2}\right.$ ) corresponded to $7.5 \%$ of the sample, while the overweight percentage was $47.2 \%$. The mean BMI differed significantly between day workers and shift workers. Exposure time to shift work was significant, and this finding led us to infer that age as well as shift work years contributed to BMI in an independent and positive way ${ }^{(4)}$. Shift work duration seems to be positively associated with BMI and waist:hip ratio in male and female populations independent of age, sex, smoking status, physical activity and education ${ }^{(11)}$. In Oriental male workers with sedentary functions, shift work, smoking status and marital status were associated with BMI increase. Shift work, excessive alcohol consumption and decrease in physical activity were significantly associated with an increase in waist:hip ratio ${ }^{(12)}$. Based on these findings, we can conclude that even in Oriental societies overweight and obesity dimensions can reach alarming proportions. On the other hand, Nakamura et al. compared the BMI of shift workers and day workers and could not corroborate these findings ${ }^{(13)}$. The reason may be attributed to the origins of this population, since this research was carried out in an Oriental society, where overweight and obesity do not occur in the same proportions seen in Western populations. Interestingly, they found a difference in the waist:hip ratio, where shift workers showed higher measures. It is important to know if shift work in this population could have an influence on fat distribution, rather than BMI, suggesting possible alterations in lipid metabolism.

In comparing 226 nurses and 134 male shift workers from a factory, obesity was found to be 2.8 and $27.9 \%$, respectively $^{(14)}$. We noticed limitations, such as sample heterogeneity. Differences in sex, socio-economic status and schooling could have influenced obesity. These observations may have contributed to the establishment of weak associations. Nurses aged 30 years or more showed a significant association between time in shift work and waist:hip ratio ${ }^{(14)}$. The reason may be the fact that components such as the wake-sleep cycle, thermogenesis, food intake, and lipid and glucose metabolism are under circadian regulation. This regulation synchronises available and expenditure energy to external changes in the environment, such as the light-dark phase ${ }^{(15)}$. Such rhythms are coordinated by circadian clocks which are intrinsically maintained by molecular mechanisms whose objective is to condition humans to adapt to environmental changes. Circadian clock components have been found in all kinds of mammalian tissues, including adipose tissue. Recent studies suggest a relationship between altered eating habits, wake-sleep pattern, lifestyle and obesity. This relationship may explain the increase in obesity ${ }^{(16)}$. Work schedules that involve the alteration of typical working hours are related to a natural sleep-wake cycle disruption, exposing humans to light periods during atypical hours, promoting an irregular food intake pattern and modifying shift workers' social and family routines.
It is known that shift work displays a role in the increase of $\mathrm{BMI}$; therefore we propose, according to the findings focused in several variables analysed in these studies, that age, time of exposure, the time in which someone works, strain of job and psychosocial factors may contribute to potentialise the increase in anthropometric parameters.

\section{Shift work and circadian cycle disruption}

The major function of the circadian system is the internal cycling of physiological and metabolic events. In fact, many physiological processes display day-night rhythms. Feeding behaviour and lipid and carbohydrate metabolism are subject to daily variation, showing a circadian pattern ${ }^{(17)}$. The temporal organisation of the human body has to be understood to appreciate the impact of night and shift work on humans. The body has not only structure in space as expressed by its gross and microscopic anatomy, but it also has a structure in time consisting of rhythms of numerous frequencies superimposed on trends of development and ageing ${ }^{(5)}$.

The temporal organisation of organic functions accounts for each activity being carried out during a particular hour of the day. This fact creates a series of controlled and rigorous procedures. The rhythmic variations encountered vary in period from milliseconds, as in individual nerve cells, to minutes or hours (ultradian rhythms) and to longer periods as in the menstrual cycle in women and seasonal periods (circannual rhythms) in both men and women. The rhythms most studied are related to $24 \mathrm{~h}$, which determines the circadian rhythm expression proposed by Halberg ${ }^{(18)}$. Many of these rhythms are genetically fixed and the genes and their products have been characterised in different mammalian species and in humans. Like the sleep-wake cycle, feeding behaviour is under circadian control ${ }^{(19-26)}$. Some studies have shown the influence of circadian rhythm of feeding behaviour on body-weight regulation. For example, obese animal models show this disruption in feeding rhythm ${ }^{(27,28)}$.

In all phyla, circadian rhythms have been demonstrated and species-specific dedicated clock genes have been found in model systems by reverse genetics. In humans, the mechanisms of the molecular clock remain hypothetical, as identification of human clock genes are predominantly based on their sequence similarity with those in other animals ${ }^{(29)}$. In mammals, a clock centre (pacemaker) resides in the suprachiasmatic nucleus (SCN) located above the crossing of the optic nerves. The circadian clock controls physiology from gene expression to complex behaviours (for example, sleep and performance). This internal control is synchronised to the exogenous environment through signals, such as transient night and day cycles, where light is captured by retinal and transduced to the SCN via collaterals of the optic nerve where they synchronise the circa-daily rhythm produced by SCN neurons to exactly $24 \mathrm{~h}$. Via its rhythmic outputs, the SCN coordinates all the cellular circadian clocks, including clocks from adipose tissue, to adapt physiology to the Earth's rotation ${ }^{(29)}$

Circadian molecular clocks driven by autoregulatory transcription-translation feedback loops consist of a pair of activator proteins, CLOCK and BMAL-1, in mammals that 
induce the transcription of a pair of repressor genes Per and Cry, additionally regulated by modifiers ${ }^{(30)}$. These proteins have been found in the neural circadian master clock, SCN, and in several peripheral tissues including the adipose ${ }^{(31)}$. The peripheral clocks are synchronised through sympathetic outputs and the controlled secretion of circulating glucocorticoids, melatonin, and other mediators. These peripheral clock genes are similar to those present in the SCN neurons, although only the latter seem to be self-sustained. It is still unclear how these peripheral clocks are synchronised by the central SCN clock $^{(31,32)}$. Recent molecular studies revealed the direct coupling of clock genes and the regulation of metabolism ${ }^{(31-33)}$. Genetic mutations or deletions have implicated the peripheral clock genes in the regulation of glucose homeostasis ${ }^{(34)}$, lipid synthesis $^{(35)}$ and adipogenesis ${ }^{(36)}$, which are associated with obesity and type 2 diabetes mellitus. The role for Bmall and Clock in the regulation of glucose homeostasis was shown through the inactivation of the known clock components Bmall (Mop3) and Clock suppressing the diurnal variation in glucose and TAG. Gluconeogenesis is abolished by deletion of Bmall and is depressed in Clock mutants, but the feedback response of corticosterone and glucagon to insulin-induced hypoglycaemia is retained. In addition, a high-fat diet modulates carbohydrate metabolism by amplifying circadian variation in glucose tolerance and insulin sensitivity ${ }^{(34)}$. These genes are enrolled in the control of insulin-induced hypoglycaemia. Furthermore, when dietary cues are desynchronised, as happens in shift workers, the modification of metabolic homeostasis occurs via interactions of these genes with peripheral molecular clocks.

The mechanisms underlying internal desynchronisation have been mainly investigated in experimental animals with protocols that induce phase shifts of the light-dark cycle and thus modify the activity of the SCN. SalgadoDelgado et al. ${ }^{(37)}$ developed an animal model of night work in which the light-dark cycle remained stable and where rats were required to be active in a rotating wheel for $8 \mathrm{~h}$ daily during their sleeping phase. This group was compared with rats that worked in the wheel during their activity phase and with undisturbed rats. They provided evidence that forced activity during the sleeping phase alters not only activity, but also the temporal pattern of food intake. As a consequence, these rats showed a loss of glucose rhythmicity and a reversed rhythm of TAG. In contrast, rats that worked during their activity phase did not show such changes and exhibited metabolic rhythms similar to those of the controls. The authors suggest that, in night workers, the combination of work and eating during working hours may be the cause of internal desynchronisation ${ }^{(37)}$. This response takes place once the complete adaptation to the inversed phase is practically impossible. In shift work, central and peripheral oscillators must adapt to a new rhythmicity imposed by the work schedule. This modification requires time. Human rhythms are synchronised to diurnal activity by the environmental light-dark cycle and social routine, then undergo phase readjustment when forced to adhere to a new sleep-wake pattern. The central and peripheral oscillators will try to follow the new schedule, but this adaptation does not occur immediately. It is necessary for some sleep-wake cycles to adjust to the changed phase of the environmental synchroniser. It is known that even after a prolonged duration of time on shift, only a minority of night workers shows phase adaptation of their circadian system to the nocturnal activity pattern. The majority either shows no change in most of the variables examined or shows a rhythm disruption with some intermediate phase alterations ${ }^{(5,38)}$.

The circadian rhythms of individuals synchronise the environment through the light-dark phase and social rhythm. In night-day alterations, such as in shift workers, alterations in social routine and/or meal times are described as desynchronisation. Different rhythms previously synchronised express themselves in different periods, where central and peripheral oscillators must adapt to a new rhythmicity. This modification demands some time. Rhythms of an individual, synchronised to diurnal activity by the environmental light-dark cycle and social routine, must undergo phase readjustment when forced to adhere to a new activity-sleep schedule due to shift work, for example. Symptoms comparable with jet lag, with gastrointestinal complaints, fatigue and sleepiness are often experienced by shift workers during the scheduled wake periods, and poor sleep during the daytime sleep attempts ${ }^{(39)}$. The explanation of the phenotypic expression of obesity is a complex mechanism which involves mutations of clock genes, altered glucosic and lipidic metabolism, reduced thermogenic response due to a night eating pattern and disruption of neurohumoral factors, such as leptin and ghrelin and desynchronisation of clock genes presented in adipocyte cells. The disease model of shift work proposed in the present study is shown in Fig. 2.

\section{Shift work and eating pattern}

Some studies suggest indirectly that the metabolic efficiency of the diet is different depending on the time that food is eaten ${ }^{(38,40-55)}$. It was shown in the same subjects that there was a relative body-weight gain in humans when food was available only in the evening as compared with availability in the morning ${ }^{(47)}$.

Studies of the effects of shift work on eating habits and nutritient intake have previously been conducted $^{(46,51,52,55-57)}$. Most studies did not find a difference between shift workers and daytime workers with respect to their total energy intake and their macronutrient intake. Instead, many reports found that there were changes in eating habits and food selection in shift workers. A crosssectional study found that among subjects aged 30 years or more, the total energy intake was the highest among shift workers involved in midnight shifts. They did not find significant differences in nutrient intakes between day workers and shift workers without a midnight shift. It seems that the impact of shift work on nutrient intake differed by age and the type of shift work ${ }^{(52)}$.

Workers who usually eat more energy in the evening seem to have a greater body weight. An experimental study was conducted to measure energy expenditure in nine nonobese young men selected randomly to receive a meal in one of three sessions $(09.00,17.00$ or 01.00 hours). The snacks 


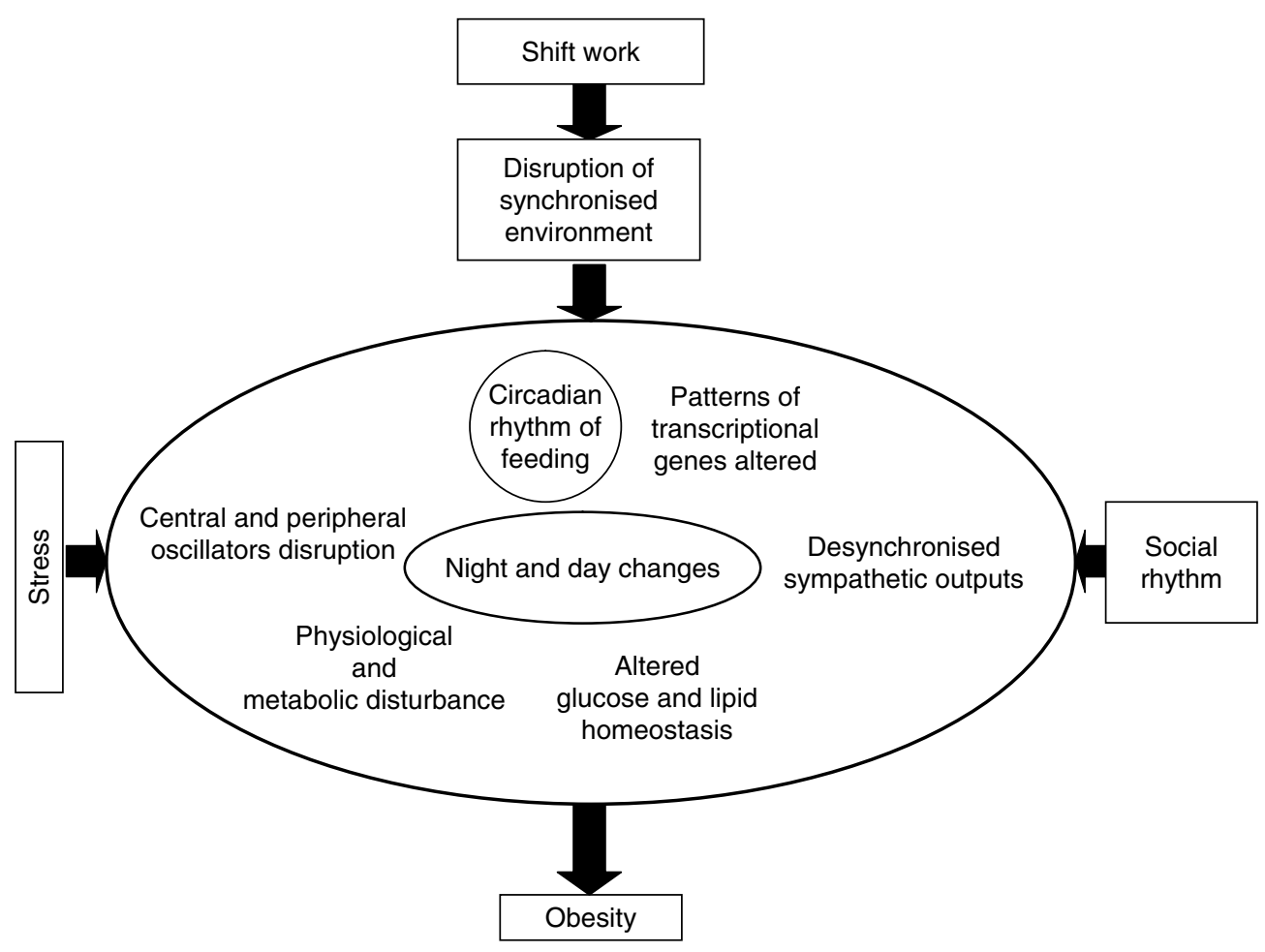

Fig. 2. The disease model of shift work adapted from Knutsson ${ }^{(39)}$.

were the same for all participants. Energy expenditure was measured by indirect calorimetry $1 \mathrm{~h}$ before and for $6 \mathrm{~h}$ after the snack. The study showed a clear difference in the energy expenditure response to the same meal, depending on the circadian stage during which it was consumed. Morning diet-induced thermogenesis was significantly higher compared with afternoon and night. Therefore, the time at which a meal is consumed may affect the thermogenic response ${ }^{(47)}$. This fact may be related to shift workers' weight gain, since they seem to show a desynchronisation in lipid consumption during the day and a higher intake of this macronutrient through foods such as snacks. Associated with changes regarding eating pattern, sleep deprivation may contribute to the acceleration or triggering of metabolic disturbances, such as glucose intolerance, insulin resistance and dyslipidaemia ${ }^{(58)}$.

Besides that, genes regulate body weight and food intake. The general model of intake regulation also involves environmental and psychological factors such as the social facilitation of eating, diurnal rhythms of intake, anxiety traits and restrained behaviour ${ }^{(59)}$. The role of genetics in shift work has not been clear until now; however, we can hypothesise that the phenomenon of desynchronisation may involve the genic expression of these genes, contributing to shift workers' increased body weight and waist circumference. This idea corroborates the findings concerning shift workers' eating patterns and suggests the delay of entrainment of rhythms coordinated by these genes. Further experimental research should investigate how these genes response to a desynchronised model.

\section{Shift work $v$. metabolic disturbances}

Shift work is accompanied by a greater incidence of many medical disorders such as cardiovascular, metabolic, gastrointestinal and sleep disorders ${ }^{(39,60-65)}$. Previous studies have demonstrated that risks increase according to exposure, such as hypertension, diabetes, coronary artery disease and weight gain ${ }^{(8,66,67)}$.

Apparently, the risk of shift work has been equated to the risk of smoking one pack of cigarettes per d. Coronary artery disease rates rise with exposure to shift work, even when controlled for other risk factors and confounding variables $^{(68)}$

Some studies have demonstrated a relationship between shift work and metabolic alterations ${ }^{(41,48,69-78)}$. A study evaluating insulin resistance showed that shift workers who were aged 50 years old or younger showed insulin resistance more frequently than day workers ${ }^{(71)}$. Another study, involving 300 workers from an Austrian refinery, demonstrated a prevalence of endocrine and metabolic diseases among shift workers of about $3.5 \%: 1.5 \%$ in day workers and $2.8 \%$ in workers who alternated shifts ${ }^{(77)}$.

The Third Report of the National Cholesterol Education Program Expert Panel on Detection, Evaluation, and Treatment of High Blood Cholesterol in Adults (ATP III) highlights the importance of treating patients with the metabolic syndrome to prevent $\mathrm{CVD}^{(78)}$. The constellation of metabolic abnormalities, called the metabolic syndrome, includes glucose intolerance (impaired glucose tolerance, or impaired fasting glucose), insulin resistance, central obesity, dyslipidaemia and hypertension, predisposing subjects to an 
increased risk of type 2 diabetes and $\mathrm{CVD}^{(78)}$. Because of variations in definitions and samples studied, the prevalence of the metabolic syndrome in some studies differed. Analysis of data from the Third National Health and Nutrition Examination Survey (1988-94), based on 8814 subjects aged 20 years or older, found, after adjustment for age, a metabolic syndrome prevalence of $23.7 \%$. This prevalence increased from $6.7 \%$ among participants aged $20-29$ years to $43.5 \%$ for participants aged $60-69$ years. It seems that sex did not make a difference to metabolic syndrome diagnosis: in men, $24.0 \%$; in women, $23.4 \%$. The 2000 census data showed that 47 million US residents have the metabolic syndrome ${ }^{(79)}$.

The most accepted and unifying hypothesis to describe the pathophysiology of the metabolic syndrome is insulin resistance. Insulin resistance has traditionally been defined from a glucocentric view, i.e. a defect in insulin action results in fasting hyperinsulinaemia to maintain euglycaemia. Yet, even before fasting hyperinsulinaemia develops, postprandial hyperinsulinaemia exists. A major contributor to the development of insulin resistance is an overabundance of circulating fatty acids. Fatty acids are also derived through the lipolysis of TAG-rich lipoproteins in tissues by the action of lipoprotein lipase. Insulin is important to both antilipolysis and the stimulation of lipoprotein lipase. Of note, the most sensitive pathway of insulin action is the inhibition of lipolysis in adipose tissue. Thus, when insulin resistance develops; the increased amount of lipolysis of stored TAG molecules in adipose tissue produces more fatty acids, which could further inhibit the antilipolytic effect of insulin, creating additional lipolysis. Upon reaching insulinsensitive tissues, excessive fatty acids create insulin resistance by the added substrate availability and by modifying downstream signalling ${ }^{(80)}$.

Previous studies have shown an association between shift work and lipid profile disturbances, where these disturbances could be due to internal desynchronisation ${ }^{(45,54,76)}$. Subjects who worked three shifts showed higher total cholesterol and TAG levels than did day workers and fulltime workers. The authors reported that $69 \%$ of three-shift workers did not engage in any physical recreational activity. Three-shift work was independently associated with total cholesterol $^{(76)}$. Perhaps stress, a common condition in these individuals, could induce hypercholesterolaemia. Another possibility is that shift workers' food intake is more abundant in cholesterol, since it is known that their lipid consumption is higher than regular workers ${ }^{(56,57)}$. Research has shown that high serum total cholesterol and LDLcholesterol levels were more common in shift workers than in day workers. This finding persisted after adjustment was made for age and food type. However, in disagreement with other authors, this study did not show difference in the prevalence of HDL-cholesterol, TAG and fasting blood glucose and hypertension between shift working and day working ${ }^{(76)}$.

The fact that shift workers present a chronically reversed sleep-wake cycle may be associated with the higher incidence of the metabolic syndrome in this population $^{(70,81)}$. The imposed desynchronisation may be responsible for changes in the metabolism and secretion patterns of endocrine factors. This circadian rhythm in neurological, endocrine, thermoregulatory and other body functions may resynchronise only slowly after the abrupt phase shift common to rotating shift work.

Shift work is related to circadian rhythmicity disruption, which occurs with alterations in one or more of the pathological components of the metabolic syndrome ${ }^{(10,82)}$. Deletion of the Clock and Bmall genes results not only in circadian disruption, but also in metabolic abnormalities of lipid and glucose homeostasis - a phenotype similar to the metabolic syndrome ${ }^{(34,35)}$ - which suggests that this clock disruption directly influences the metabolism. This is supported by a study that reported the development of the metabolic syndrome in Clock mutant mice ${ }^{(35)}$, showing that a loss of function in this gene results in altered patterns of food intake. Then, these animals present an increase in their food consumption, becoming obese and developing hyperglycaemia and dyslipidaemia. The parallel also occurs in the development of adipocyte hypertrophy. It seems that mutations in Bmall and Clock not only modify the diurnal variation in levels of plasma glucose and TAG, but also influence the progress of glucose impairment and insulin resistance, once submitted to a high-fat diet. Apparently the total energy intake of shift workers is not the problem, as their consumption is very similar to that of day workers. We hypothesise that the composition of food associated with night eating may play a role more relevant than the energy. This statement is evidenced by studies regarding food intake. Individuals engaged in this kind of labour pattern do not eat more energy than day workers, but they present an elevated consumption of snacks, which are high-fat meals. This kind of food behaviour becomes even more noxious considering the time that meals are taken, which explains such alterations presented in shift workers.

Physical inactivity and overweight/obesity contribute approximately $50 \%$ to the insulin resistance process and glucose intolerance in healthy, normotensive and nondiabetic subjects ${ }^{(73)}$. Other factors that may contribute to these disturbances are being studied, such as alterations in cyclic endocrine rhythms involved in shift work. In healthy subjects, glucose tolerance decreases during the day. Studies have shown that both glucose and insulin responses seem to be mediated by circadian rhythms ${ }^{(21)}$.

Studies have found that the insulin response to glucose may result in $\beta$-cell circadian alterations, producing a responsive that is greater in the morning and decreases during the day ${ }^{(43)}$. Shift work as well as shift workers' behaviour may lead to the disruption of the endocrine circadian rhythm, such as levels of glucose ${ }^{(75,83,84)}$, insulin $^{(49,71,75)}$, leptin ${ }^{(85-89)}, \mathrm{TAG}^{(69,70,76,83)}$, and total cholesterol $^{(13,54,70,76)}$ and its fractions ${ }^{(54,83)}$. Besides, Copertaro et al. found a higher prevalence of the metabolic syndrome among shift workers than daytime workers, when using the International Diabetes Federation diagnostic criteria. In accordance with these data, shift workers were also more likely than regular workers to have a high waist circumference $^{(83)}$

Despite the fact that Di Lorenzo et al. ${ }^{(2)}$ found a relationship between shift work and BMI, they were unable to reproduce this finding with regard to total cholesterol serum levels, TAG and HDL-cholesterol. These results may be attributed to differences in dietary habits and also to 
genetic differences related to geographic region. On the other hand, both TAG and HDL-cholesterol were independently associated with serum insulin concentration. These results permitted a connection between insulin resistance and higher TAG and lower HDL-cholesterol, indicating the metabolic syndrome. Insulin levels were significantly associated with BMI, but there was no relation to shift work. The authors hypothesised that shift work could have a role in BMI and body fat increase, producing insulin resistance and altering glucose metabolism. Systolic blood pressure and glucose tolerance differed significantly in shift workers $^{(2)}$. Unfortunately, systolic blood pressure was not analysed in a chronobiological scope. Therefore, its increase in shift workers could be explained by either rhythm desynchronisation or overweight or an interaction between the two variables. In conclusion, even in the Mediterranean region, shift work exerts an influence on obesity, CVD and the metabolic syndrome.

Subjects who worked three shifts showed higher total cholesterol and TAG levels than did day workers and fulltime workers. The authors reported that $69 \%$ of three-shift workers did not engage in any physical recreational activity. Three-shift work was independently associated with total cholesterol $^{(76)}$. Perhaps stress, a common condition in these individuals, could induce hypercholesterolaemia. Another possibility is that shift workers' food intake is more abundant in cholesterol, since it is known that their lipid consumption is higher than regular workers ${ }^{(56,57)}$. Research has shown that high serum total cholesterol and LDLcholesterol levels were more common in shift workers than in day workers. This finding persisted after adjustment was made for age and food type. However, there was no difference in the prevalence of HDL-cholesterol, TAG and fasting blood glucose and hypertension between shift working and day working. The authors concluded that shift work is a risk factor for lipid profile disturbances ${ }^{(76)}$

In the meantime, shift workers present higher BMI and waist circumference than day workers. These results may suggest a role played by shift work on the development and/or the early clinic manifestations of metabolic disturbances, becoming a risk factor for the metabolic syndrome.

In chronobiological approach it is important to highlight that the hormones leptin and ghrelin, anorexin and orexin are secreted, as are the majority of hormones, in a circadian pattern $^{(25,26,32,33,72,86,89-94)}$. Then we may hypothesise that light exposure at night could contribute to a decreased and/or delay in the secretion of leptin, which is secreted usually at night with its acrophasis at around midnight. This could contribute to an enhanced hunger and food intake pattern associated with an increase in ghrelin levels, leading to weight gain and visceral fat accumulation in the abdominal region. Simultaneously with stress, job strain and psychosocial factors, shift workers are then predisposed to cortisol hypersecretion, with hyperstimulation from the hypothalamic-pituitary-adrenal axis leading adipose tissue to produce even more fat tissue. Simultaneously, metabolic disturbances could be due to desynchronised rhythm or shift workers' lifestyle, or both. In fact, stress and lifestyle are potent mediators in the development of metabolic conditions in shift workers.
The existence of an active circadian clock in adipocytes suggests that there is a temporal component to the regulation of adipose tissue function. Recent evidence connecting circadian dysfunction to obesity and the metabolic syndrome strongly supports this notion ${ }^{(34,35)}$. Metabolism and maintenance of energy homeostasis require functional coordination among individual adipose depots and other metabolically active tissue sites, to ensure proper nutrient/ energy flux and substrate use by the organism. Desynchronisation produced by feeding or alternative entrainment mechanisms may lead to defective substrate use, resulting in the disruption of metabolic pathways leading to intramyocellular lipid accumulation, and insulin resistance.

Experimental studies may be very helpful to understand these mechanisms. For example, inverting the sleep-wake cycle and food intake pattern of animals may provide evidence that hormones concerning body weight, adipose tissue and food intake suffer the circadian misalignment provoked by the alteration of the light-dark cycle. Further research similar to that proposed above may be able to investigate new conceptions and possible mechanisms supporting the chronobiological argument of a disruption on the pacemakers, including the oscillators present in adipocytes.

\section{Discussion}

Shift work has long been unrecognised as an occupational health hazard up until now. Currently research in the field has shown limited evidence available, due to underpowered studies, since the most common design was cross-sectional. Articles analysed did not describe protocols to control anthropometric measures, which could cause bias and impairment in the interpretation of data, since variables such as weight and height were self-reported. Studies involving body weight must show a cohesive and accurate design, mostly because a series of variables, such as lifestyle and eating habits, may be strong confounding factors. Also, the inclusion of subjects with different lifestyles accounts for biases, even though they may be from the same work place. Concerning sample selection, authors must minimise potential confounders. It is important to maintain homogeneity between shift group and control group for years on shift, age and a detailed anamnesis about previous body weight and clinical and surgical treatments for weight control. However, we were able to demonstrate associations between shift work and increases in BMI and metabolic disturbances, supported by experimental studies that had a more rigorous design.

Obesity now represents the most prevalent nutritional problem, with a prevalence of 300 million adults worldwide, given the limited availability of effective treatment of weight problems. It is known that this pathology consists of a strong risk factor for lipidic profile disturbances, central obesity, insulin resistance, circulatory disease and the metabolic syndrome. At the core of the association between the sleep-wake cycle and obesity may be a molecular mechanism intrinsic to all eukaryotic cells and organisms, namely circadian oscillators. Recent investigations suggest that the causes of obesity involve a complex interplay of genetic, environmental, psychobehavioural, endocrine, metabolic, cultural and socio-economic factors. Recently, 


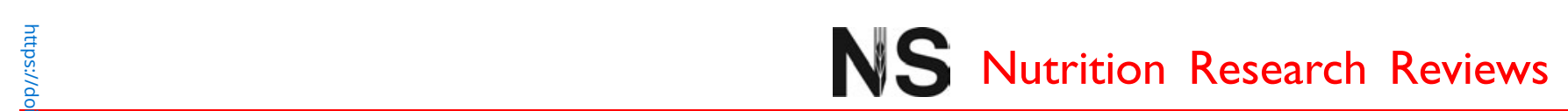

Table 1. Overview of studies on the effects of shift work on BMI, circadian disruption and metabolic disturbances

\begin{tabular}{|c|c|c|c|c|c|c|c|}
\hline Reference & Study & Study design & Variables & Outcome & $\begin{array}{l}\text { Sample } \\
\text { size }\end{array}$ & Conclusion & Sample \\
\hline $\begin{array}{l}\text { De Bacquer et al. } \\
(2009)^{(60) *}\end{array}$ & Prospective study & $\begin{array}{l}\text { Epidemiological } \\
\text { cohort }\end{array}$ & Shift work & $\begin{array}{l}\text { Metabolic } \\
\text { syndrome }\end{array}$ & 1529 & $\begin{array}{l}\text { Prospective evidence } \\
\text { was found that rotating } \\
\text { shift work increases the } \\
\text { risk for developing the } \\
\text { metabolic syndrome over } \\
\text { a period of } 6 \text { years }\end{array}$ & $\begin{array}{l}\text { Employees from } \\
\text { several large } \\
\text { Belgian } \\
\text { companies }\end{array}$ \\
\hline \multirow[t]{2}{*}{$\begin{array}{l}\text { Biggi et al. } \\
\qquad(2008)^{(70) *}\end{array}$} & $\begin{array}{l}\text { Retrospective } \\
\text { (2328 medical } \\
\text { examinations } \\
\text { between } 1976 \\
\text { and 2007) }\end{array}$ & Longitudinal & Shift work & BMI & 488 & $\begin{array}{l}\text { Night workers smoked more } \\
\text { and had significantly } \\
\text { higher BMI, serum total } \\
\text { cholesterol, and TAG }\end{array}$ & Male workers \\
\hline & & & & $\begin{array}{l}\text { Total cholesterol } \\
\text { TAG }\end{array}$ & & & \\
\hline $\begin{array}{l}\text { Copertaro et al. } \\
\qquad(2008)^{(96)_{\star}}\end{array}$ & Diagnostic & Cross-sectional & $\begin{array}{l}\text { Shift work } \\
\text { and the } \\
\text { metabolic } \\
\text { syndrome }\end{array}$ & CVD risk & 147 & $\begin{array}{l}\text { The increased risk of CVD } \\
\text { associated with shift work is } \\
\text { related to the greater } \\
\text { incidence of the metabolic } \\
\text { syndrome among these } \\
\text { workers. In this study a } \\
\text { high prevalence of the } \\
\text { metabolic syndrome was } \\
\text { detected only with the IDF }\end{array}$ & \\
\hline $\begin{array}{l}\text { Morikawa et al. } \\
\qquad(2008)^{(52)} \dagger\end{array}$ & & Cross-sectional & Shift work & Nutrient intake & 2254 & $\begin{array}{l}\text { The impact of shift work on } \\
\text { nutrient intakes differed } \\
\text { by age and the type } \\
\text { of shift work }\end{array}$ & $\begin{array}{l}\text { Male manual } \\
\text { workers }\end{array}$ \\
\hline $\begin{array}{l}\text { Salgado-Delgado et al. } \\
\qquad(2008)^{(37)} \ddagger\end{array}$ & & Experimental & Shift work & $\begin{array}{l}\text { Internal desynchronisation } \\
\text { at the metabolic and } \\
\text { behavioural level }\end{array}$ & 44 & $\begin{array}{l}\text { The combination of work } \\
\text { and eating during shift } \\
\text { working hours may be } \\
\text { the cause of internal } \\
\text { desynchronisation }\end{array}$ & Male Wistar rats \\
\hline $\begin{array}{l}\text { Sookoian et al. } \\
\qquad(2007)^{(97) *}\end{array}$ & Diagnostic & Cross-sectional & Shift work & $\begin{array}{l}\text { Leucocyte count, and } \\
\text { risk factors } \\
\text { for the metabolic } \\
\text { syndrome }\end{array}$ & 1351 & $\begin{array}{l}\text { Rotating shift workers } \\
\text { had elevated BMI, } \\
\text { WHR, diastolic arterial } \\
\text { blood pressure and } \\
\text { fasting insulin }\end{array}$ & $\begin{array}{l}\text { Male subjects } \\
\text { recruited from } \\
\text { a factory }\end{array}$ \\
\hline \multirow[t]{2}{*}{$\begin{array}{l}\text { Ghiasvand et al. } \\
\qquad(2006)^{(76) \star}\end{array}$} & Diagnostic & Cross-sectional & Shift work & Total cholesterol & 424 & $\begin{array}{l}\text { High serum total cholesterol } \\
\text { and LDL-cholesterol } \\
\text { levels were more common } \\
\text { in shift workers. Shift work } \\
\text { is a risk factor for lipid } \\
\text { profile disturbances }\end{array}$ & Rail road workers \\
\hline & & & & $\begin{array}{l}\text { TAG } \\
\text { Fasting blood glucose }\end{array}$ & & & \\
\hline $\begin{array}{l}\text { Tüchsen et al. } \\
\qquad(2006)^{(62) \star}\end{array}$ & Prospective study & Cohort & Shift work & Risk for circulatory disease & 5517 & $\begin{array}{l}\text { Shift work carries an } \\
\text { excess risk of } \\
\text { circulatory diseases }\end{array}$ & $\begin{array}{l}\text { Random sample } \\
\text { drawn from the } \\
\text { Central } \\
\text { Population } \\
\text { Register of } \\
\text { Denmark }\end{array}$ \\
\hline
\end{tabular}




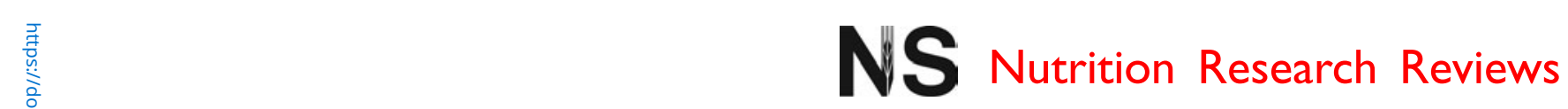

Shift work

Wolk \& Somers

$(2007)^{(73) *}$

Review

Review

Sleep

Sharifian et al.

$(2005)^{(1)} \S$

Aetiological

Cross-sectional

Shift work

Ha \& Park (2005) $)^{(14) \star ~}$

Shift work

Aetiological

Wilsgaard et al

$(2005)^{(9)}$

Shea et al.

$(2005)^{(72)} \ddagger$
Experimental

Glucose, insulin

and leptin
Pathological conditions

Metabolic syndrome

Plasma antioxidan

capacity, age

and weight

Metabolic syndrome

risk factors

There is a large association between shift work and the prevalence of many medical conditions

Sleep curtailment and shift

work have detrimental

metabolic consequences,

may have important

implications for

population-based

approaches to combat
the epidemic of metabolic

the epidemic of metabolic
and cardiovascular

disease

220

hift work can act as an

special diet, including

360

BMI

7965

Significant associations

Alterations in the

adipokines and glucose

sleep-wake regulation oxidative stressor. A

antioxidant agents,

may be beneficial to

shift workers

here is an association

between shift work

duration and metabolic

risk factors for CVD

between several lifestyle

BMI change revealed that

observed baseline

associations were strength

ened over time, especially

in women

sleep-wake schedule

would lead to an increased

Industrial

catering

male

personne

Female

hospital

nurses and

male

blue-collar

workers at a

firm manu

facturing

diapers and

feminine

hygiene

materials

Subjects from

Tromsø,

Norway

daily range in circu

leptin, with lowest leptin

upon awakening, which,

by influencing food intake

and energy balance, could

be implicated in the

increased prevalence of

obesity in the shift work

population 


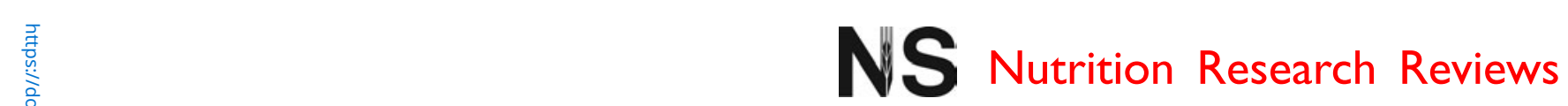

Table 1. Continued

\begin{tabular}{|c|c|c|c|c|c|c|c|}
\hline Reference & Study & Study design & Variables & Outcome & $\begin{array}{l}\text { Sample } \\
\text { size }\end{array}$ & Conclusion & Sample \\
\hline \multirow[t]{2}{*}{$\begin{array}{l}\text { Ishizaki et al. } \\
\qquad(2004)^{(12)} \S\end{array}$} & Diagnostic & Cross-sectional & $\begin{array}{l}\text { Work } \\
\quad \text { characteristics }\end{array}$ & WHR & 6676 & $\begin{array}{l}\text { BMI was associated with } \\
\text { shift work, marital status } \\
\text { and sedentary job for } \\
\text { males, and with exercise } \\
\text { but inversely associated } \\
\text { with education for females. } \\
\text { WHR was also associated } \\
\text { with shift work, alcohol } \\
\text { consumption, marital } \\
\text { status and sedentary job } \\
\text { but inversely associated } \\
\text { with exercise for males, } \\
\text { and with sedentary job, } \\
\text { marital status and education } \\
\text { but inversely associated } \\
\text { with smoking for females }\end{array}$ & $\begin{array}{l}\text { Workers from a } \\
\text { metal product } \\
\text { factory }\end{array}$ \\
\hline & & & & BMI & & & \\
\hline $\begin{array}{l}\text { Pasqua \& Moreno } \\
\qquad(2004)^{(51)} \dagger\end{array}$ & Longitudinal & Cross-sectional & Shift work & $\begin{array}{l}\text { Eating habits in two } \\
\text { different seasons: } \\
\text { winter and summer }\end{array}$ & 28 & $\begin{array}{l}\text { Food consumption was } \\
\text { significantly higher in winter } \\
\text { than summer. No statistically } \\
\text { significant differences were } \\
\text { found among shifts and the } \\
\text { interaction effect between } \\
\text { shift and season was also } \\
\text { not significant }\end{array}$ & $\begin{array}{l}\text { Employees from } \\
\text { maintenance } \\
\text { department } \\
\text { of a subway } \\
\text { railway } \\
\text { transport } \\
\text { company }\end{array}$ \\
\hline $\begin{array}{l}\text { Di Lorenzo et al. } \\
(2003)^{(2) *} \S\end{array}$ & Diagnostic & Cross-sectional & Shift work & $\begin{array}{l}\text { BMI, WHR, glucose, } \\
\text { insulin, total } \\
\text { cholesterol, } \\
\text { HDL-cholesterol, } \\
\text { TAG, glucose } \\
\text { levels during } \\
75 \mathrm{~g} \text { oral glucose } \\
\text { tolerance } \\
\text { test, systolic and } \\
\text { diastolic } \\
\text { blood pressure }\end{array}$ & 718 & $\begin{array}{l}\text { Shift work may be directly } \\
\text { responsible for increased } \\
\text { body fatness and is indirectly } \\
\text { associated with higher blood } \\
\text { pressure levels and some } \\
\text { features of the metabolic } \\
\text { syndrome }\end{array}$ & $\begin{array}{l}\text { Workers from } \\
\text { an industry } \\
\text { located in } \\
\text { Southern } \\
\text { Italy }\end{array}$ \\
\hline Knutsson $(2003)^{(39) *}$ & Review & Review & Shift work & Medical disorders & - & $\begin{array}{l}\text { Health problems in this } \\
\text { population could also be } \\
\text { mediated by sleep problems. } \\
\text { Lifestyle and stress are } \\
\text { potential mediators of } \\
\text { disease in shift workers }\end{array}$ & - \\
\hline $\begin{array}{l}\text { Karlsson et al. } \\
\qquad(2003)^{(69) \star}\end{array}$ & Diagnostic & Cross-sectional & Shift work & Metabolic disturbances & 1324 & $\begin{array}{l}\text { A significant association } \\
\text { was found between shift } \\
\text { work and lipid disturbances. } \\
\text { Authors did not find any } \\
\text { association with } \\
\text { hyperglycaemia }\end{array}$ & $\begin{array}{l}\text { A subpopulation } \\
\text { from the } \\
\text { WOLF study }\end{array}$ \\
\hline
\end{tabular}




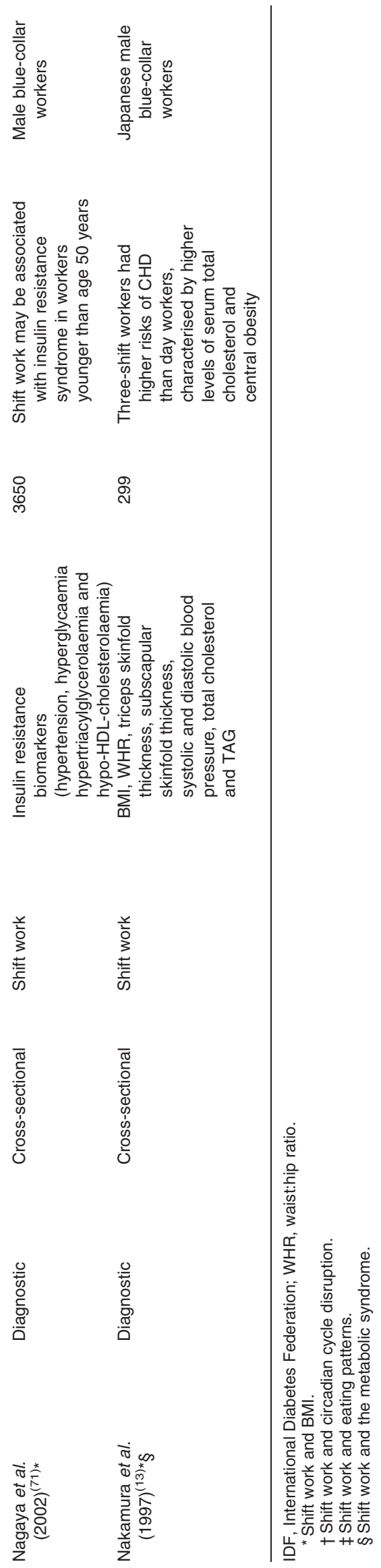

circadian oscillator genes in adipose tissue have brought significant metabolic implications; their characterisation may provide potential therapeutic relevance. Current treatments for obesity have been largely unsuccessful in maintaining long-term weight loss, demonstrating the urgent need for new insight into mechanisms that may lead to obesity and altered metabolism. From now on, it is important to provide guidelines concerning a better adaptation and to monitor shift work to reduce its risks. The field of occupational medicine must design a specific protocol composed of clinical and laboratorial features presented in shift workers. The clinical examination should be done with a more frequent periodicity. For example, it would be helpful if shift workers were submitted to an evaluation directed to screening the metabolic syndrome, diabetes mellitus and CVD. A biochemical protocol involving total cholesterol, HDL-cholesterol, LDL-cholesterol, TAG and glucose serum may be supportive to an early diagnosis or to identify subjects at an increased risk of the development of these pathologies. Mainly, it is essential to take a very careful look at minimising alterations in these biochemical features. Anthropometric measures, such as body weight, BMI and waist circumference, should also be taken in a clinical examination. In order to minimise damage, companies should provide dietary and lifestyle counselling, promoting healthier habits. Those companies that provide snacks and/or meals during shifts should make a dietary plan specifically for shift workers, once their risks concerning metabolic disturbances are known. An exercise programme could promote a better lifestyle, becoming a protection factor to the maintenance of shift workers' health. A sleep education programme could also be interesting to encourage sleep hygiene practices. With regard to shift schedule, intervention studies indicated that the introduction of a better schedule improves biomarkers related to the metabolic syndrome, while a worse shift schedule promotes weight gain in this population ${ }^{(95)}$.

The role of the circadian clock mechanism in metabolic conditions in shift workers represents an exciting new field of study in pursuit of the causes of the increasing prevalence of obesity. The elucidation of the link between the circadian clock disruption and metabolic disturbances in shift workers may have profound implications on the timing of obesity therapies. Future studies are needed to elucidate circadian alterations in shift workers, although it is also essential to have a rigorous design concerning sample homogeneity and the variables examined.

Table 1 summarises articles covering topics featured in the present review.

\section{Acknowledgements}

The present review was supported by the Graduate Research Group (GPPG) at Hospital de Clínicas de Porto Alegre, Brazil.

The authors thank the Post-Graduation Program in Medical Sciences, School of Medicine, Universidade Federal do Rio Grande do Sul (UFRGS), Porto Alegre, Brazil and Fundo de Incentivo à Pesquisa e Eventos (FIPE) at Hospital de Clínicas de Porto Alegre, Brazil, for supporting the present review. 
L. C. A. designed the study, wrote the protocol, reviewed studies, drafted the article and interpreted the data. R. L. and G. D. were responsible for drafting the article. W. C. and M. P. H. participated in study design, drafting the article and final approval of this version.

There was no financial relationship between any of the authors or any commercial interest in the outcome of the present study.

\section{References}

1. Sharifian A, Farahani S, Pasalar P, et al. (2005) Shift work as an oxidative stressor. J Circadian Rhythms 3, 15.

2. Di Lorenzo L, De Pergola G, Zocchetti C, et al. (2003) Effect of shift work on body mass index: results of a study performed in 319 glucose-tolerant men working in a Southern Italian industry. Int J Obes Relat Metab Disord 27, 1353-1358.

3. Ostry AS, Radi S, Louie AM, et al. (2006) Psychosocial and other working conditions in relation to body mass index in a representative sample of Australian workers. BMC Public Health 6, 53.

4. Parkes KR (2002) Shift work and age as interactive predictors of body mass index among offshore workers. Scand $J$ Work Environ Health 28, 64-71.

5. Haus E \& Smolensky M (2006) Biological clocks and shift work: circadian dysregulation and potential long-term effects. Cancer Causes Control 17, 489-500.

6. Beersma DG \& Gordijn MC (2007) Circadian control of the sleep-wake cycle. Physiol Behav 90, 190-195.

7. World Health Organization (1997) Obesity: Preventing and Managing the Global Epidemic. Report of a WHO Consultation Group on Obesity. Geneva: WHO.

8. Morikawa Y, Nakagawa H, Miura K, et al. (2007) Effect of shift work on body mass index and metabolic parameters. Scand $J$ Work Environ Health 33, 45-50.

9. Wilsgaard T, Jacobsen BK \& Arnesen E (2005) Determining lifestyle correlates of body mass index using multilevel analyses: the Tromso Study, 1979-2001. Am J Epidemiol 162, 1179-1188.

10. Karlsson B, Knutsson A \& Lindahl B (2001) Is there an association between shift work and having a metabolic syndrome? Results from a population based study of 27485 people. Occup Environ Med 58, 747-752.

11. van Amelsvoort LG, Schouten EG \& Kok FJ (1999) Duration of shiftwork related to body mass index and waist to hip ratio. Int J Obes Relat Metab Disord 23, 973-978.

12. Ishizaki M, Morikawa Y, Nakagawa H, et al. (2004) The influence of work characteristics on body mass index and waist to hip ratio in Japanese employees. Ind Health 42, 41-49.

13. Nakamura K, Shimai S, Kikuchi S, et al. (1997) Shift work and risk factors for coronary heart disease in Japanese bluecollar workers: serum lipids and anthropometric characteristics. Occup Med (Lond) 47, 142-146.

14. Ha M \& Park J (2005) Shiftwork and metabolic risk factors of cardiovascular disease. J Occup Health 47, 89-95.

15. Gomez-Abellan P, Hernandez-Morante JJ, Lujan JA, et al. (2008) Clock genes are implicated in the human metabolic syndrome. Int J Obes (Lond) 32, 121-128.

16. Bray MS \& Young ME (2007) Circadian rhythms in the development of obesity: potential role for the circadian clock within the adipocyte. Obes Rev 8, 169-181.
17. Sookoian S, Gemma C, Fernandez Gianotti T, et al. (2007) Effects of rotating shift work on biomarkers of metabolic syndrome and inflammation. J Intern Med 261, 285-292.

18. Halberg F (1976) Chronobiology in 1975. Chronobiologia 3 , $1-11$.

19. Follenius M, Brandenberger G \& Hietter B (1982) Diurnal cortisol peaks and their relationships to meals. J Clin Endocrinol Metab 55, 757-761.

20. Froy O (2007) The relationship between nutrition and circadian rhythms in mammals. Front Neuroendocrinol $\mathbf{2 8}$, 61-71.

21. Fukushima M, Lupien J \& Bray GA (1985) Interaction of light and corticosterone on food intake and brown adipose tissue of the rat. Am J Physiol 249, R753-R757.

22. Hau M \& Gwinner E (1996) Food as a circadian Zeitgeber for house sparrows: the effect of different food access durations. J Biol Rhythms 11, 196-207.

23. Johnson BC (1992) Nutrient intake as a time signal for circadian rhythm. J Nutr 122, 1753-1759.

24. Strubbe JH \& Woods SC (2004) The timing of meals. Psychol Rev 111, 128-141.

25. Stutz AM, Staszkiewicz J, Ptitsyn A, et al. (2007) Circadian expression of genes regulating food intake. Obesity (Silver Spring) 15, 607-615.

26. Yang S, Liu A, Weidenhammer A, et al. (2009) The role of $m P e r 2$ clock gene in glucocorticoid and feeding rhythms. Endocrinology 150, 2153-2160.

27. Yoshimatsu H, Machidori H, Doi T, et al. (1993) Abnormalities in obese Zuckers: defective control of histaminergic functions. Physiol Behav 54, 487-491.

28. Hanada R, Teranishi H, Pearson JT, et al. (2004) Neuromedin $\mathrm{U}$ has a novel anorexigenic effect independent of the leptin signaling pathway. Nat Med 10, 1067-1073.

29. Allebrandt KV \& Roenneberg T (2008) The search for circadian clock components in humans: new perspectives for association studies. Braz J Med Biol Res 41, 716-721.

30. Lamont EW, Legault-Coutu D, Cermakian N, et al. (2007) The role of circadian clock genes in mental disorders. Dialogues Clin Neurosci 9, 333-342.

31. Kohsaka A \& Bass J (2007) A sense of time: how molecular clocks organize metabolism. Trends Endocrinol Metab 18, 4-11.

32. Zvonic S, Ptitsyn AA, Conrad SA, et al. (2006) Characterization of peripheral circadian clocks in adipose tissues. Diabetes 55, 962-970.

33. Yang X, Downes M, Yu RT, et al. (2006) Nuclear receptor expression links the circadian clock to metabolism. Cell 126, 801-810.

34. Rudic RD, McNamara P, Curtis AM, et al. (2004) BMAL1 and CLOCK, two essential components of the circadian clock, are involved in glucose homeostasis. PLoS Biol 2, e377.

35. Turek FW, Joshu C, Kohsaka A, et al. (2005) Obesity and metabolic syndrome in circadian Clock mutant mice. Science 308, 1043-1045.

36. Shimba S, Ishii N, Ohta Y, et al. (2005) Brain and muscle Arnt-like protein-1 (BMAL1), a component of the molecular clock, regulates adipogenesis. Proc Natl Acad Sci USA 102, 12071-12076.

37. Salgado-Delgado R, Angeles-Castellanos M, Buijs MR, et al. (2008) Internal desynchronization in a model of night-work by forced activity in rats. Neuroscience 154, 922-931.

38. Simon C, Weibel L \& Brandenberger G (2000) Twenty-fourhour rhythms of plasma glucose and insulin secretion rate in regular night workers. Am J Physiol Endocrinol Metab 278, E413-E420. 
39. Knutsson A (2003) Health disorders of shift workers. Occup Med (Lond) 53, 103-108.

40. Weststrate JA, Weys PJ, Poortvliet EJ, et al. (1989) Diurnal variation in postabsorptive resting metabolic rate and dietinduced thermogenesis. Am J Clin Nutr 50, 908-914.

41. Weibel L \& Brandenberger G (1998) Disturbances in hormonal profiles of night workers during their usual sleep and work times. J Biol Rhythms 13, 202-208.

42. Terman M, Gibbon J, Fairhurst S, et al. (1984) Daily meal anticipation: interaction of circadian and interval timing. Ann N Y Acad Sci 423, 470-487.

43. Smith GP (2000) The controls of eating: a shift from nutritional homeostasis to behavioral neuroscience. Nutrition 16, 814-820.

44. Scheer FA, Hilton MF, Mantzoros CS, et al. (2009) Adverse metabolic and cardiovascular consequences of circadian misalignment. Proc Natl Acad Sci USA 106, 4453-4458.

45. Romon M, Le Fur C, Lebel P, et al. (1997) Circadian variation of postprandial lipemia. Am J Clin Nutr 65, 934-940.

46. Romon M, Beuscart R, Frimat P, et al. (1986) Caloric intake and weight gain according to the shift schedule of shift workers (article in French). Rev Epidemiol Sante Publique 34, 324-331.

47. Romon M, Edme JL, Boulenguez C, et al. (1993) Circadian variation of diet-induced thermogenesis. Am J Clin Nutr $\mathbf{5 7}$ $476-480$.

48. Ribeiro DC, Hampton SM, Morgan L, et al. (1998) Altered postprandial hormone and metabolic responses in a simulated shift work environment. J Endocrinol 158, 305-310.

49. Qin LQ, Li J, Wang Y, et al. (2003) The effects of nocturnal life on endocrine circadian patterns in healthy adults. Life Sci 73, 2467-2475.

50. Plata-Salaman CR \& Oomura Y (1987) Food intake dependence on acute changes in light schedule. Physiol Behav 41, 135-140.

51. Pasqua IC \& Moreno CR (2004) The nutritional status and eating habits of shift workers: a chronobiological approach. Chronobiol Int 21, 949-960.

52. Morikawa Y, Miura K, Sasaki S, et al. (2008) Evaluation of the effects of shift work on nutrient intake: a cross-sectional study. J Occup Health 50, 270-278.

53. Morgan L, Hampton S, Gibbs M, et al. (2003) Circadian aspects of postprandial metabolism. Chronobiol Int 20, 795-808.

54. Lennernas M, Akerstedt T \& Hambraeus L (1994) Nocturnal eating and serum cholesterol of three-shift workers. Scand $J$ Work Environ Health 20, 401-406.

55. Lennernas M, Hambraeus L \& Akerstedt $T$ (1995) Shift related dietary intake in day and shift workers. Appetite 25, 253-265.

56. de Assis MA, Nahas MV, Bellisle F, et al. (2003) Meals, snacks and food choices in Brazilian shift workers with high energy expenditure. J Hum Nutr Diet 16, 283-289.

57. de Assis MA, Kupek E, Nahas MV, et al. (2003) Food intake and circadian rhythms in shift workers with a high workload. Appetite 40, 175-183.

58. Crispim CA, Zalcman I, Dáttilo M, et al. (2007) The influence of sleep and sleep loss upon food intake and metabolism. Nutr Res Rev 20, 195-212.

59. de Castro JM (2004) Genes, the environment and the control of food intake. Br J Nutr 92, Suppl. 1, S59-S62.

60. De Bacquer D, Van Risseghem M, Clays E, et al. (2009) Rotating shift work and the metabolic syndrome: a prospective study. Int J Epidemiol 38, 848-854.
61. Keith SW, Redden DT, Katzmarzyk PT, et al. (2006) Putative contributors to the secular increase in obesity: exploring the roads less traveled. Int J Obes (Lond) 30, 1585-1594.

62. Tüchsen F, Hannerz H \& Burr H (2006) A 12 year prospective study of circulatory disease among Danish shift workers. Occup Environ Med 63, 451-455.

63. van Mark A, Spallek M, Kessel R, et al. (2006) Shift work and pathological conditions. J Occup Med Toxicol 1, 25.

64. Marquie JC \& Foret J (1999) Sleep, age, and shiftwork experience. J Sleep Res 8, 297-304.

65. Conway PM, Campanini P, Sartori S, et al. (2008) Main and interactive effects of shiftwork, age and work stress on health in an Italian sample of healthcare workers. Appl Ergon 39, 630-639.

66. Morikawa Y, Nakagawa H, Miura K, et al. (2005) Shift work and the risk of diabetes mellitus among Japanese male factory workers. Scand J Work Environ Health 31, 179-183.

67. Morikawa Y, Nakagawa H, Miura K, et al. (1999) Relationship between shift work and onset of hypertension in a cohort of manual workers. Scand J Work Environ Health 25, 100-104

68. Whitehead DC, Thomas H Jr \& Slapper DR (1992) A rational approach to shift work in emergency medicine. Ann Emerg Med 21, 1250-1258.

69. Karlsson BH, Knutsson AK, Lindahl BO, et al. (2003) Metabolic disturbances in male workers with rotating threeshift work. Results of the WOLF study. Int Arch Occup Environ Health 76, 424-430.

70. Biggi N, Consonni D, Galluzzo V, et al. (2008) Metabolic syndrome in permanent night workers. Chronobiol Int 25, 443-454.

71. Nagaya T, Yoshida H, Takahashi H, et al. (2002) Markers of insulin resistance in day and shift workers aged 30-59 years. Int Arch Occup Environ Health 75, 562-568.

72. Shea SA, Hilton MF, Orlova C, et al. (2005) Independent circadian and sleep/wake regulation of adipokines and glucose in humans. J Clin Endocrinol Metab 90, 2537-2544.

73. Wolk R \& Somers VK (2007) Sleep and the metabolic syndrome. Exp Physiol 92, 67-78.

74. Lund J, Arendt J, Hampton SM, et al. (2001) Postprandial hormone and metabolic responses amongst shift workers in Antarctica. $J$ Endocrinol 171, 557-564.

75. Morgan L, Arendt J, Owens D, et al. (1998) Effects of the endogenous clock and sleep time on melatonin, insulin, glucose and lipid metabolism. $J$ Endocrinol 157, 443-451.

76. Ghiasvand M, Heshmat R, Golpira R, et al. (2006) Shift working and risk of lipid disorders: a cross-sectional study. Lipids Health Dis 5, 9.

77. Koller M, Kundi M \& Cervinka R (1978) Field studies of shift work at an Austrian oil refinery. I: Health and psychosocial wellbeing of workers who drop out of shiftwork. Ergonomics 21, 835-847.

78. Expert Panel on Detection, Evaluation, and Treatment of High Blood Cholesterol in Adults (2001) Executive Summary of The Third Report of The National Cholesterol Education Program (NCEP) Expert Panel on Detection, Evaluation, and Treatment of High Blood Cholesterol in Adults (Adult Treatment Panel III). JAMA 285, 2486-2497.

79. Ford ES, Giles WH \& Dietz WH (2002) Prevalence of the metabolic syndrome among US adults: findings from the third National Health and Nutrition Examination Survey. JAMA 287, 356-359.

80. Eckel RH, Grundy SM \& Zimmet PZ (2005) The metabolic syndrome. Lancet 365, 1415-1428.

81. Holmback U, Forslund A, Lowden A, et al. (2003) Endocrine responses to nocturnal eating - possible implications for night work. Eur J Nutr 42, 75-83. 
82. Tanofsky-Kraff M \& Yanovski SZ (2004) Eating disorder or disordered eating? Non-normative eating patterns in obese individuals. Obes Res 12, 1361-1366.

83. Copertaro A, Bracci M, Barbaresi M, et al. (2008) Role of waist circumference in the diagnosis of metabolic syndrome and assessment of cardiovascular risk in shift workers (article in Italian). Med Lav 99, 444-453.

84. Muller MB, Keck ME, Zimmermann S, et al. (2000) Disruption of feeding behavior in CRH receptor 1-deficient mice is dependent on glucocorticoids. Neuroreport 11, $1963-1966$.

85. Asakuma S, Hiraku O, Kurose Y, et al. (2004) Diurnal rhythm of cerebrospinal fluid and plasma leptin levels related to feeding in non-lactating and lactating rats. $J$ Endocrinol 180, 283-286.

86. Baskin DG, Figlewicz Lattemann D, Seeley RJ, et al. (1999) Insulin and leptin: dual adiposity signals to the brain for the regulation of food intake and body weight. Brain Res $\mathbf{8 4 8}$, 114-123.

87. Choi YH, Li C, Hartzell DL, et al. (2008) ICV leptin effects on spontaneous physical activity and feeding behavior in rats. Behav Brain Res 188, 100-108.

88. Dube MG, Xu B, Kalra PS, et al. (1999) Disruption in neuropeptide $\mathrm{Y}$ and leptin signaling in obese ventromedial hypothalamic-lesioned rats. Brain Res 816, 38-46.

89. Motivala SJ, Tomiyama AJ, Ziegler M, et al. (2009) Nocturnal levels of ghrelin and leptin and sleep in chronic insomnia. Psychoneuroendocrinology 34, 540-545.
90. Inyushkin AN, Bhumbra GS \& Dyball RE (2009) Leptin modulates spike coding in the rat suprachiasmatic nucleus. J Neuroendocrinol 21, 705-714.

91. Ptitsyn AA \& Gimble JM (2007) Analysis of circadian pattern reveals tissue-specific alternative transcription in leptin signaling pathway. BMC Bioinformatics 8, Suppl. 7, S15.

92. Goel N, Stunkard AJ, Rogers NL, et al. (2009) Circadian rhythm profiles in women with night eating syndrome. $J$ Biol Rhythms 24, 85-94.

93. Kalsbeek A, Fliers E, Romijn JA, et al. (2001) The suprachiasmatic nucleus generates the diurnal changes in plasma leptin levels. Endocrinology 142, 2677-2685.

94. Natalucci G, Riedl S, Gleiss A, et al. (2005) Spontaneous 24-h ghrelin secretion pattern in fasting subjects: maintenance of a meal-related pattern. Eur J Endocrinol 152, $845-850$.

95. Boggild H \& Jeppesen HJ (2001) Intervention in shift scheduling and changes in biomarkers of heart disease in hospital wards. Scand J Work Environ Health 27, 87-96.

96. Copertaro A, Bracci M, Barbaresi M, et al. (2008) Assessment of cardiovascular risk in shift healthcare workers. Eur J Cardiovasc Prev Rehabil 15, 224-229.

97. Sookoian S, Gemma C, Fernandéz Gianotti T, et al. (2007) Effects of rotating shift work on biomarkers of metabolic syndrome and inflammation. J Intern Med 261, 285-292. 